\title{
ASEISMIC DESIGN OF 24 STOREY HOTEL "DE-LUXE“", SKOPJE
}

\author{
Dr. Miodrag Velkov*
}

\begin{abstract}
This paper represents the structural design and dynamic analysis of a 24 storey hotel in Skopje. Applying the latest conceptions for seismic stability and safety of structures, i.e. the plasticity criteria and plastic excursion deformations, the design of the structural system was accomplished. The system itself is a reinforced concrete frame combined with R.C. framed walls. The framed walls are so designed, as to act as seismic energy absorbers.

The mathematical model was formulated by electronic computer, while the input data concerning the stiffness characteristics and deformations of the infilled walls are based on experimental results obtained in Japan.

The data obtained for the optimal system show that the structure satisfies completely all the requirements imposed by the seismicity criteria of the site of construction.
\end{abstract}

\section{EARTHQUAKE AND STRUCTURES}

Earthquakes or ground motion due to release of energy in the upper layers of the Earth crust are natural phenomena known from the beginning of the world. But, the rapid increase of the world population nowadays and the number of structures required by the technilogical development, increased the risk of devastating earthquakes. We witnessed disastrous consequences of earthquakes affecting many countries in the world during the last several years. This imposed rapid development of the earthquake engineering science and the progress made during the last ten years is considerable.

A new scientific basis has been established. It is well known today that the amount of seismic force in a structure, with theoretical elastic behaviour, during actual earthquake is 4-6 times larger than the amount of forces obtained according to the Aseismic Design Code. Namely, the structures subject to seismic forces suffer inelastic deformations due to the certain amount of ductility possessed by the structure in question. It means that the seismic stability depends upon the seismic energy accumulation capacity of the structure through elastic and very important inelastic deformations. On this basis, the concept for seismic stability of structures was formulated.

Following this principle, aseismic structures should be characterized by sufficient strength and high ductility. It can be concluded that the seismic coefficient obtained by the existing Code can be considered as appropriate, only when the structure can sustain considerable postelastic deformations. The safety criterion of aseismic structures is mainly related to the ductility

* Grad.civ.eng., Professor and Head of Section at the Institute of Earthquake Engineering and Engineering Seismology, University of Skopje, Yugoslavia. criterion.

The rapid development of computer calculation technique enabled extensive application of new methods for structural analysis. In the computer Center of the Institute of Earthquake Engineering and Engineering Seismology in Skopje, following the examples of Japan and U.S.A., a direct dynamic response analysis of structures is used. The ground motion is defined by accelerograms recorded for different types of seismic effects.

Each storey has been represented by a hysteresis loop showing the relation between the shear force and displacement. At present we mainly apply two types of diagrams:elastoplastic and bilinear ( $f i g$. 1). A system of differential equations defining the forced vibrations of masses due to ground motion has numerically been solved for each time interval of $1 / 100 \mathrm{sec}$. (fig. 2). Also the relative displacements, relative velocities and absolute accelerations were obtained for each storey separately as time variation. Hence, the capacity of the structure for postelastic deformations i.e. the ductility is the main safety criterion of structures.

The calculation of the direct dynamic response enables application of new safety criteria:elastic displacements (the ductility factor being defined as a ratio between the maximum elastoplastic displacement and displacement at the yield point), plastic excursions, which means sum of the absolute values of all plastic displacements (fig. 3). But a method which gives a better representation of the phenomenon taking place in the structure during an earthquake is the energy response calculation. This is one of the most complete methods of structural analysis based on energy capacity.

In the studies on energetic interpretation of the Skopje earthquake, basic 
equations of the energy response was set up, and worked out in an original way (fig. 4).

Using this basic energy equation, a programme of energy balance was elaborated in our Computer Center, which enabled direct application of the energy concept into the aseismic design. The time histories of the energy balance give complete representation of the safety of structures.

Furthermore, the design of a building will be explained, the structural and dynamic analysis of which was performed according to the above mentioned concept and seismic safety criteria.

\section{DESIGN PROBLEM}

The design company "Makedonijaproekt", Skopje, based on the results of a competition, started preparation of the preliminary and the final design of "De Luxe" Hotel in Skopje (Fig. 7a, 7b and 7c). Designers of this building are Dr. Miodrag Velkov and M.Sc. Predrag Gavrilovic. The objective of the design was to solve the main structural system applying the seismological data, without disturbing the architectural concept, which was a rather difficult problem for a structure over $70 \mathrm{~m}$. high. The design process is set out in figures 5 and 6 .

\section{SEISMOLOGICAL DATA}

The site of the building is in the central zone of the town, known as zone of seismic intensity IX. The terrain consists of alluvial gravel and sand sediments, well compacted, down to considerable depth. Predominant periods of ground oscillation, obtained by microtremor measurement (controlled for neighbouring structures) are from 0.30 $-0.35 \mathrm{sec}$.

In the direct dynamic analysis, recorded accelerograms and spectra of two strong earthquakes, Port Hueneme in 1957 (U.S.A.) and El Centro $1940-\mathrm{N}-\mathrm{S}$ (U.S.A.), were used as input data. These two characteristic types of earthquakes were carefully selected and adapted for the soil conditions as well as for the seismic intensity which can be expected in skopje region. Therefore, a correction of the digital data concerning the Port Hueneme earthquake was made, i.e. the time scale on the abscissa of the accelerogram was reduced for a ratio $0.35 / 0.50$, the predominant period on the accelerogram being 0.35 sec. For this modified accelerogram a velocity spectrum $S v$ was defined, which in this case is taken with intensity $\mathrm{Sv}=60 \mathrm{~cm} / \mathrm{sec}$. Data concerning $E l$ Centro earthquake were taken for intensity $70 \%$ and $100 \%$ of the real recorded intensity for duration of the seismic effect of $8 \mathrm{sec}$.

\section{STRUCTURAL SYSTEM OF THE BUILDING}

Out of many solutions given as variants of the main structural system, a variant of frame system in both orthogonal directions, with characteristic bents and sections was selected which is shown in fig. 7c. The floor structures are solved as monolithic reinforced concrete slabs. The negative effects of the infill and the staircases upon the deformation were eliminated, so the rigid walling inside the structure was avoided, and the facade concrete walls are taken as separated precast members. In this way, free deformation of the main system due to earthquake is obtained. Staircases and wall structures are separated from the building so that they have no influence upon the deformation of the frame system.

For such a system the equivalent static seismic forces were determined following the existing code, and the total design base shear force was obtained, i.e. the seismic coefficient of $C_{b}=5.208$ for the transverse and $\mathrm{C}_{b}=4.80 \%$ for the longitudinal direction. Furthermore, it was necessary to define the optimum stiffness and strength of the structural members (column sections and frame beams), taking into account the damping effects, higher mode shapes and the nonlinear work of the whole structural system. The optimization of the structural members was achieved by direct dynamic analysis applying IBM 1130 and IBM 360 computer.

The results of the analysis show that in spite of the optimum strength and stiffness characteristics (which were obtained by many trials) the structure suffers considerable damage i.e. the structural system of certain storeys enters rather deeply into the postelastic work range, with high ductility of the structural member sections. In order to increase the stability of the structure, i.e. to decrease plastic deformations, it would be necessary to increase considerably the strength capacity of the structural members (increase of the design horizontal forces) which would increase the cost of the structure.

We decided in this case, without increasing the seismic shear forces, for seismic intensity determined in advance, to avoid the plastic deformations in the main structural, system and to decrease the relative horizontal displacements of storeys. It was possible to achieve this by introduction of special RC members in a shape of thin diaphragms in the basic structural frame system.

In this case, in certain frames of the basic frame system, perforated thin diaphragms were used as partition walls of the infill, four in each frame, in the two directions of the building (Fig. 7c, diaphragms $\mathrm{D}_{1}, \mathrm{D}_{2}$, fig. 8 ).

\section{STRUCTURAL, DEFORMATIONAL AND STRENGTH CHARACTERISTICS OF THE INFILL PERFORATED DIAPHRAGMS}

As it can be seen on Figs. 7c and 8 these diaphragm walls are introduced in certain frames only. The thickness of the diaphragms is betwen 10,12 and $14 \mathrm{~cm}$; they have been separated along the edges of the frame, i.e. along the three sides and are monolithicly connected with the lower beam of the frame only (fig. 8). In this way the walls work as "shear diaphragms" which means that their influence upon the bending deformation is practically eliminated. The reinforcement of the walls was done following the ultimate state criteria, so that at the ends of the perforations plastic hinges are formed and their rotations appear due to large deformations of the whole system. 
The basic idea, i.e. concept for introduction of this thin diaphragms into the main structural system, is as follows:

1. The infill stiffness in each storey must be larger than the stiffness of the frame itself, which means an increase of the stiffness of the whole structure.

2. The strength capacity of these members must be smaller than the strength capacity of the frames. It means that postelastic deformations can be expected in these members first and after that in the frames.

3. In the postelastic work of the infill structural members (stage of first appearance of cracks) the danger of the frame joint interaction should be avoided.

4. Structural solution of these infill members should provide high deformability in the postelastic stage, i.e. after the appearance of the first cracks, especially for repeated cyclic loads, when high seismic energy absorption capacity is provided.

5. This structural solution enables an easy replacement of these members in certain storeys, in case of an earthquake without disturbing the function of the structure.

Due to the short term given for elaboration of the design and the lack of funds, the experimental results obtained in Japan (5) were used to determine the structural characteristics of the perforated diaphragms. Prof. Muto used similar types of reinforced concrete diaphragms and infilled walls in steel frames of the highest structures in Japan (Kasumigaseki and Hamamatso). Figures 9, 10 and 11 show a detail of such a wall, the experimental characteristics of stress-strain relationship and a crack pattern of the wall due to failure.

In order to explain the advantage of these diaphragms, comparison between the experimental results obtained for perforated and unperforated diaphragms was prepared. The following can be concluded: the cracks in the perforated diaphragms are uniformly distributed with a maximum width of $0.08 \mathrm{~mm}$, when the tangential stresses are

$\tau=22.5 \mathrm{~kg} / \mathrm{cm}^{2}$. For unperforated diaphragms, and the same amount of tangential stresses, the maximum width of the cracks is $0.15 \mathrm{~mm}$. The behaviour of the perforated diaphragms to unloading is excellent. It is very important that the perforated diphragms, even when the maximum tangential stresses amount $\tau=39.7 \mathrm{~kg} / \mathrm{cm}^{2}$, and displacement angle $\gamma=84.5 \times 10^{-4}$, have bearing capacity which is still sufficiently large. This shows that the ductility of this type of diaphragms is high. For unperforated diaphragms having stresses $\tau=42.5 \mathrm{~kg} / \mathrm{cm}^{2}$ and displacem.angle $\gamma=62.0, \times 10^{-} \dot{4}$, the bearing capacity suddenly decreases.

\section{INPUT DATA}

The experimental results and the loading and unloading diagram were used for definittion of the design diagram determining the force-displacement relationship, for each storey separately. So defined strength characteristics and diaphragm stiffnesses for each storey were combined with optimum stiffness and deformation results of the pure frame system. Fig. 12 shows characteristic resultant diagrams of certain storeys and directions. Using these data, direct dynamic analysis of the system subjected to actual earthquake. was carried out.

\section{RESULTS OF THE ANALYSIS}

The natural mode period of the mathematical model of structures strengthened by perforated diaphragms is $\mathrm{T}_{\text {shear }}=1.97$ and $\mathrm{T}_{\text {long }}=2.19 \mathrm{sec}$. while for a pure frame system $T_{\text {shear }}=2.24 \mathrm{sec}$. and $\mathrm{T}_{\text {long }}$ $=2.67 \mathrm{sec}$. The increase of the rigidity of the structure when perforated diaphragms are used is evident.

The structural analysis for actual earthquakes, following the heretofore mentioned criteria shows:

1. The basic supporting system of reinforced concrete frames, for defined seismic effect criteria, suffers negligible plastic deformations (for El Centro $70 \%$ and Port Hueneme SV $=60 \mathrm{~cm} / \mathrm{sec}$.) without increase of the stiffness and the amount of the total design base shear force (fig. 13 and 14). Optimum deformation characteristics in each storey of the structure were achieved by proper variation of the design shear force, the stiffness and the strength of the perforated diaphragms, so that an adequate effective ductility in each storey of the frame structure is obtained, $(\mu \max =1.30)$, fig. $13 \mathrm{~b}$.

2. Almost all considerable deformations due to seismic effects, being of high intensity take place in the perforated infilled walls. The effective ductility of the frames in certain stories shows that postelastic deformations take place in the frames too, but their amount is not so big, while the number of plastic excursions is rather small. The perforated infilled walls work postelastically. The diagrams of fig. 13 show the amount of the effective ductility, i.e. the available ductility of the perforated diaphragms of the infilled walls.

For the same seismic intensity and for the same pattern of seismic motion, the pure frame system enters deeply into the postelastic range, so that the effective ductility of certain storeys is even bigger than $3.00(\mu \max \leqslant 3.00)$, as for example in the 14 storey the transverse direction $\mu=3.50$, (fig. 15).

3. The safety criterion determined on the basis of plastic excursions, (fig. 16) shows unchanged shape of curve both for $70 \%$ intensity of the EI Centro earthquake and $100 \%$ intensity of the El Centro Earthquake. The absolute ratio of cyclic postelastic storey displacements, for design seismic intensity, is not larger than the story deformation capacity (so, considering the fifth storey, $\mathrm{Y}_{\max }=1.29$ $\mathrm{cm}$ is much smaller than the deformation capacity of the walls $\Delta{ }^{\mathrm{V}} \max >2.5 \mathrm{~cm}$ ).

In order to estimate the adequacy of the structural system and the optimalization performed, a control calculation of the mathematical model was performed, for extremely strong earthquakes although such 
strong earthquakes can hardly be expected in this region. The results of this analysis show that the amount of maximum displacements in each storey for an earthquake intensity $100 \% \mathrm{El}$ Centro is much higher, but the shape of deformation of the system remains the same, i.e. there are no excesses which would change the postelastic work of the system and the distribution of plastic deformations along the height or the position of the places where energy absorption takes place.

We should mention at the end that, this example of design is a result of the experience and knowledge obtained during many years of practical work on aseismic design of high rise buildings.

Many structures of 15 storeys and over have been designed following this concept and safety criterion, in different structural systems. Further work in the field of earthquake engineering would give different solutions of the structural systems and further improve the mathematical model and the design of the structural members in general.

\section{REFERENCES}

1. Miodrag Velkov, "Brick Masonry Ductilization in Earthquake Resistant Structures", 1970.

2. Cismigiu, Titaru, Velkov, "Energy Interpretation of the Behaviour of Structures during the Skopje Earthquake of July 26, 1963", June, 1968.

3. Cismigiu, Titaru, Velkov, "Criteria for Earthquake Resistant Codes Based on Energy Concept". (IVth World Conference on Earthquake Engineering, Santiago, Chile, 1969).

4. Kiyochi Muto, "Effects of Shear Wall in Tall Building", Feb. 1967.

5. Kiyochi Muto, "Earthquake Resistant Design of 36 storied Kasumigaseki Building, Aug. 1968 .
ELASTO-PLASTIC DIAGRAM

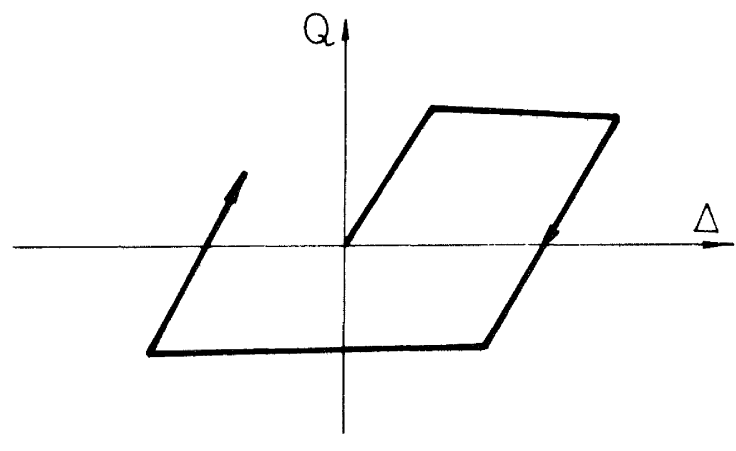

BILINEAR DIAGRAM

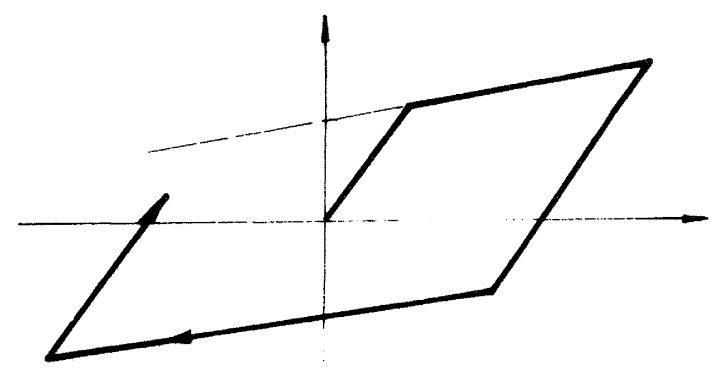

$\triangle$ - RELATIVE STOREY DISPLACEMENT

Q-TRANSVERSE STOREY FORCE

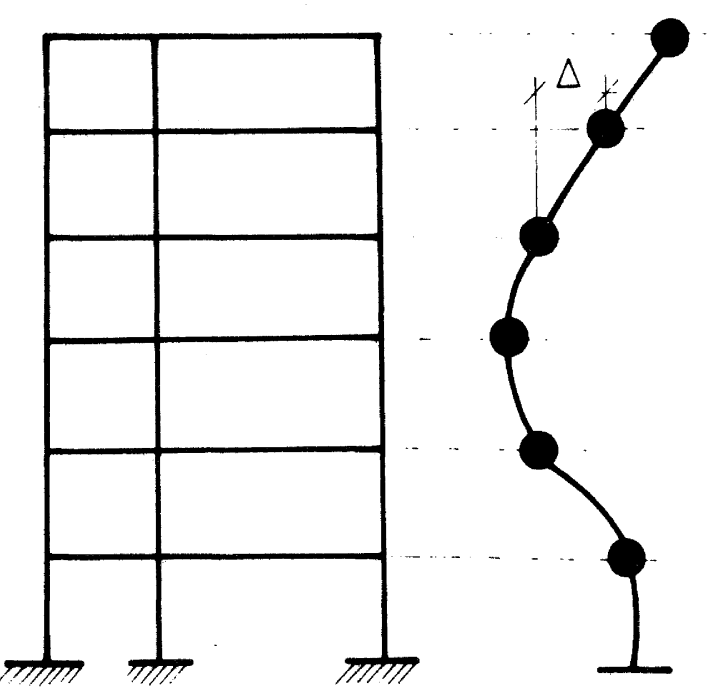

FIGURE 1: USUAL HYSTERESIS DIAGRAMS USED IN COMPUTER CALCULATION OF DYNAMIC RESPONSE 
Differential equation for the "i" storey seismic motion $m_{i} \ddot{X}_{i j+} c_{i}\left(X_{i j}-X_{i}-1\right)+K_{i}\left(X_{i j}-X_{i}-1_{j}-\varepsilon_{i}\right)+F i-c_{j+1}\left(\dot{X}_{i+1}-X_{i j}\right)-K_{i+1}\left(X_{i+1 j}-X_{i j}-\varepsilon_{i+1}\right)-F_{i+1}=m_{i} \ddot{X}_{0 j}$

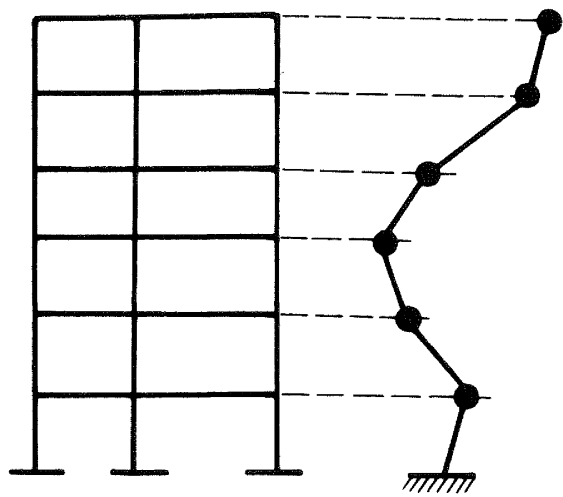

$\ddot{x}_{0 j}(t)$-ground displ. function

$X_{i j}$-relative displacements

$\dot{x}_{i j}$-relative velocity

$\ddot{x}_{i j}$-relative acceleration

mi _point " $i$ " mass

$c_{i}$-viscous damping

j -time intervac

Fig. 2 COMPUTER CALCULATION OF DYNAMIC RESPONSE; STOREY „i" EQUATION

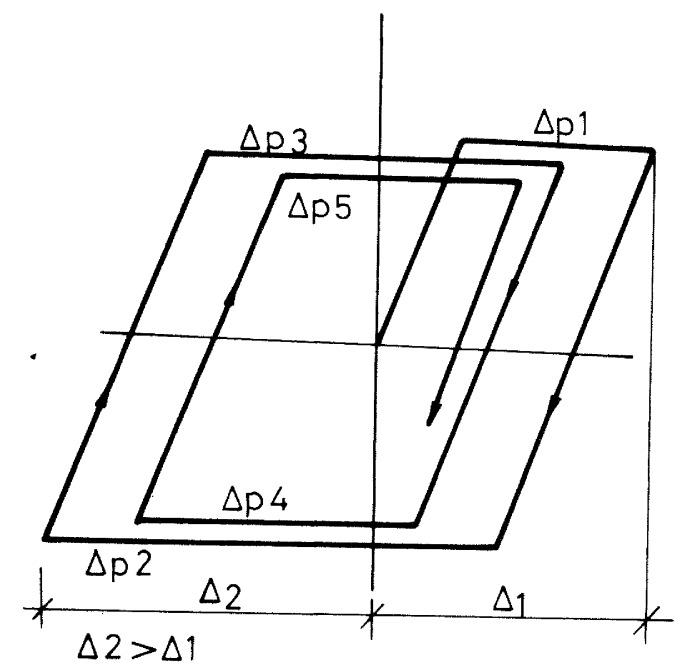

1. Criterion $\Delta \max$-max elastoplastic displacement $\Delta \max -\Delta 2$

2. Ductility factor criterion

$$
D=\frac{\Delta m a x}{\Delta y}=\frac{\Delta 2}{\Delta y}
$$

3. Plastic excursions criterion

$$
Y_{E}=\Delta p_{1}+\Delta p_{2}+\Delta p_{3}+\Delta p_{4}+\Delta p_{5}
$$

Fig. 3 SAFE TY CRITERION

Ef-suplied energy for the structure

Ek-kinetic energy of mass vibrations

Ep-accumulated potential energy during plastic deformations

Ey-absorbed energy during elasto-plastic deformations

Ev-absorbed energy during viscous friction

\section{Basic equations}

1. Differential equation of energet ic equilibrium

$$
\frac{d E f}{d t} d t=\frac{d E k}{d t} d t+\frac{d E p}{d t} d t+\frac{d E v}{d t} d t+\frac{d E_{Y}}{d t} d t
$$

2. Energetic equations

$$
E k=\int_{0}^{t} \frac{d E k}{d t} d t ; E p=\int_{0}^{t} \frac{d E p}{d t} d t ; E v=\int_{0}^{t} \frac{d E v}{d t} d t ; E Y=\cdot \int_{0}^{t} \frac{d E Y}{d t} d t
$$

Energetic equation of supplied energy for the structure $E t=E k+E p+E v+E r$ 


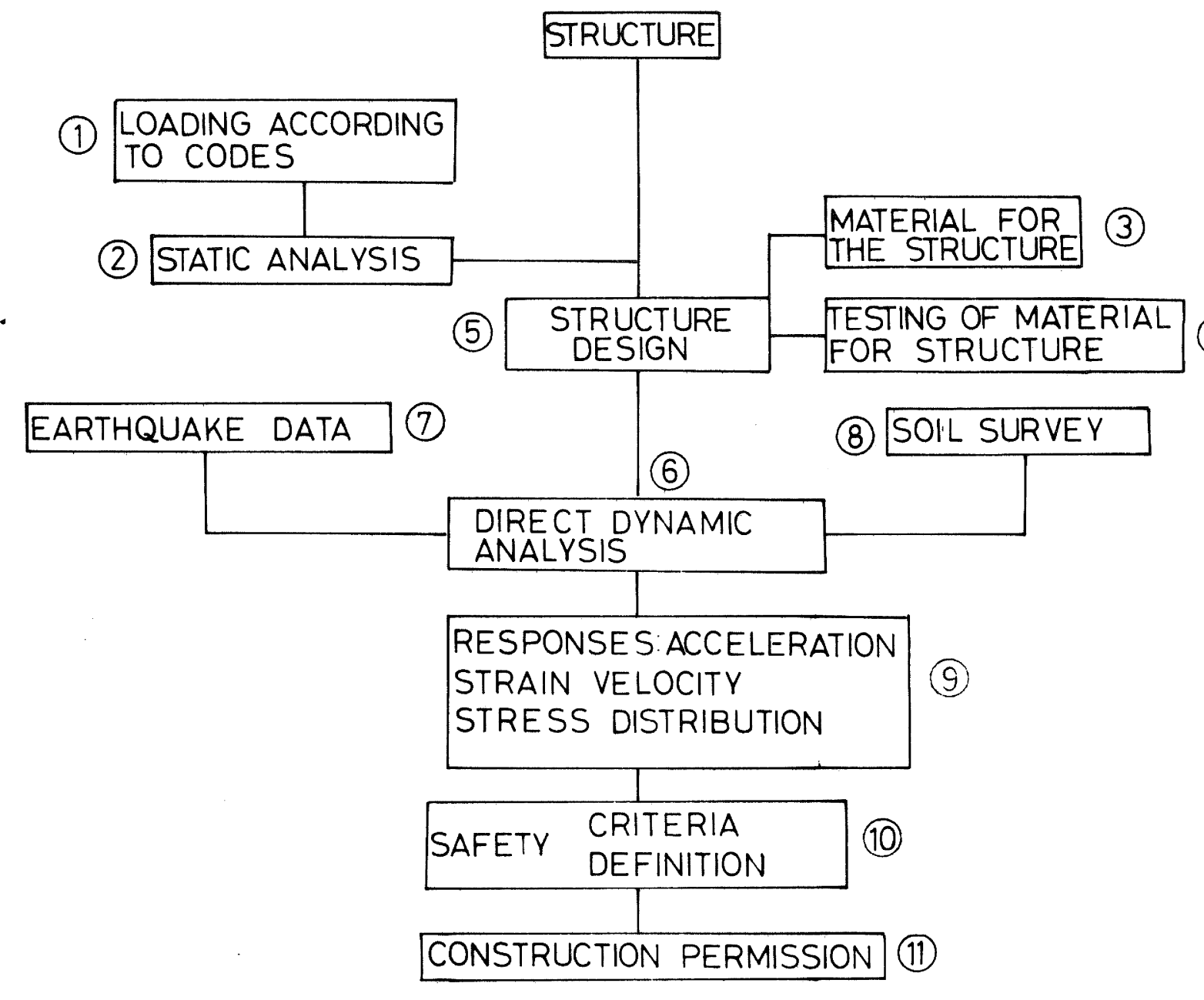

FIGURE 5

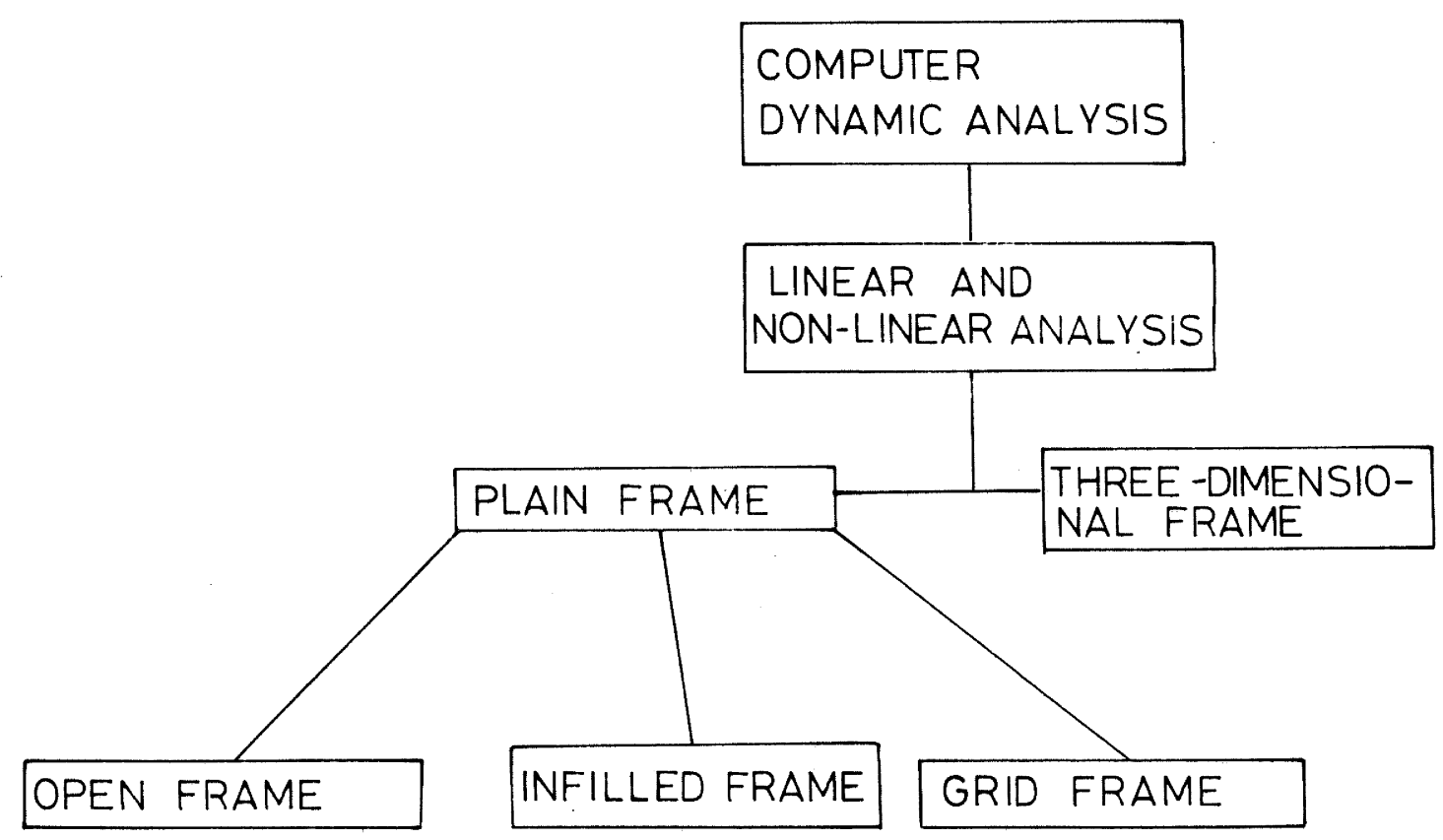

FIGURE 6 


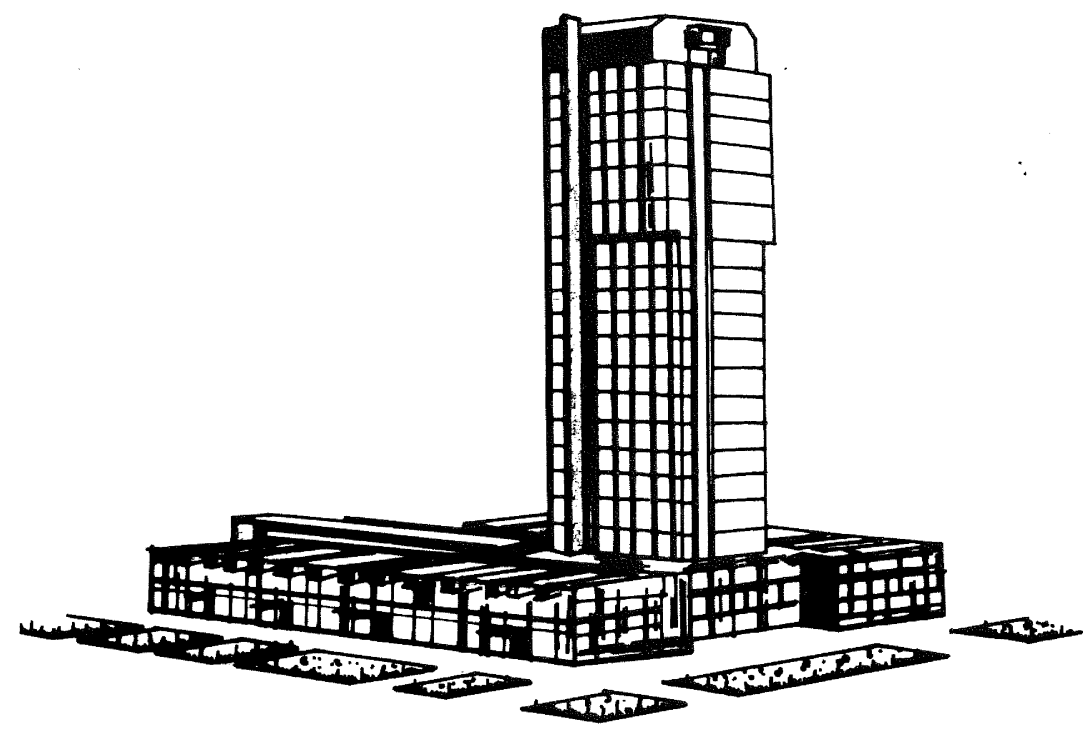

Fig.7 a. HOTEL „DE LUXE” PERSPECTIVE

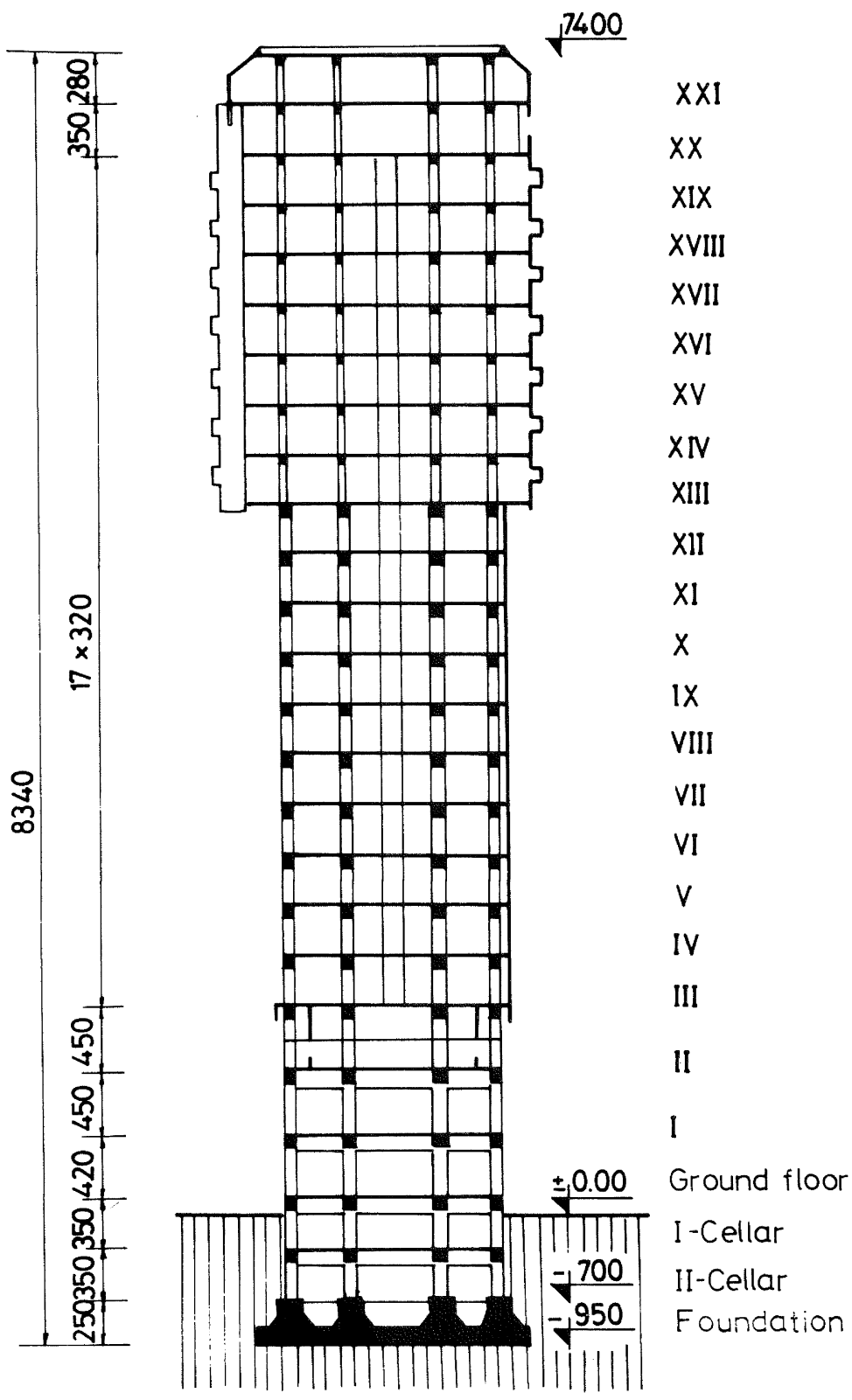

Fig. 7 b. SECTION 

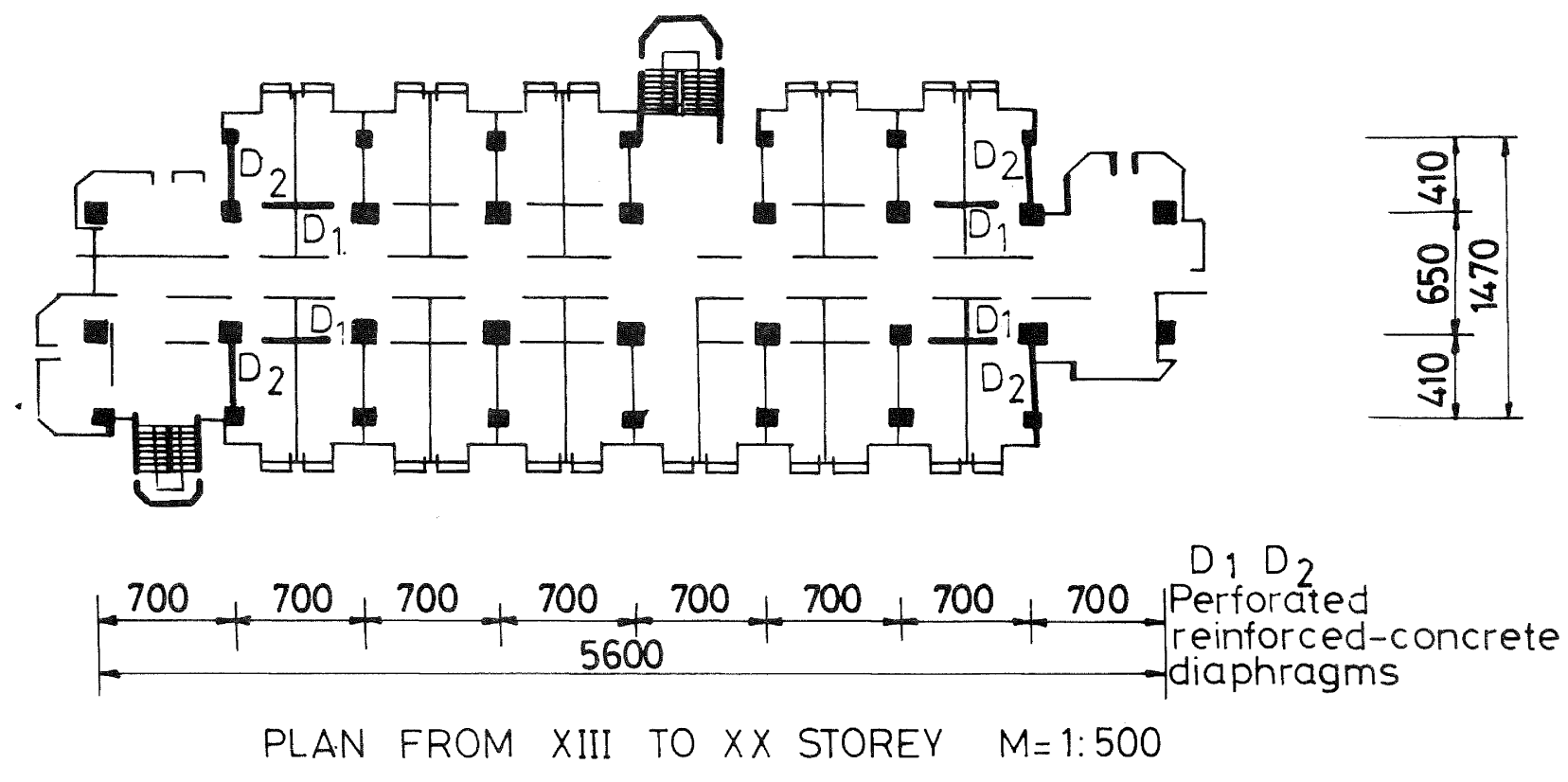

FIGURE 7: C

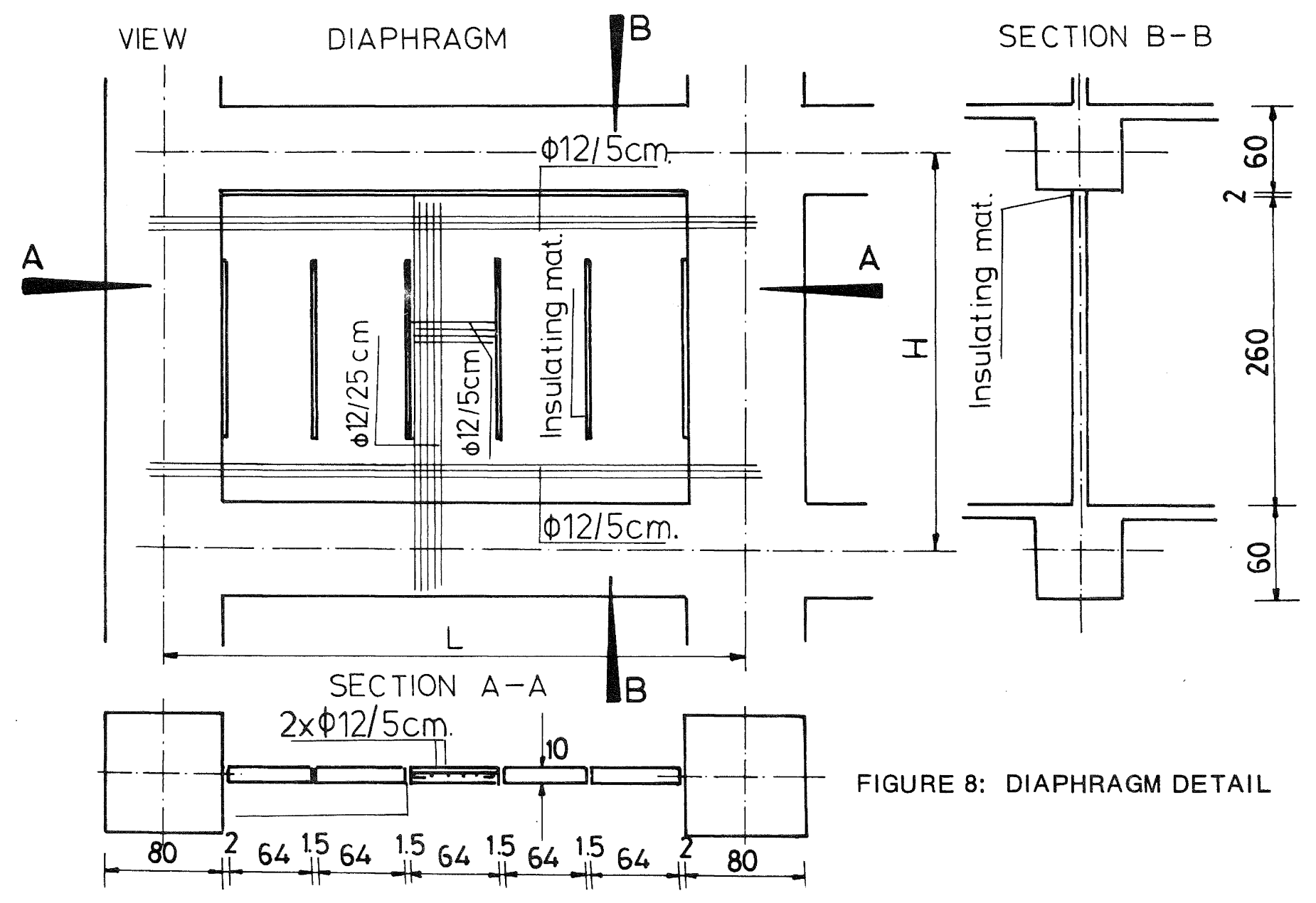




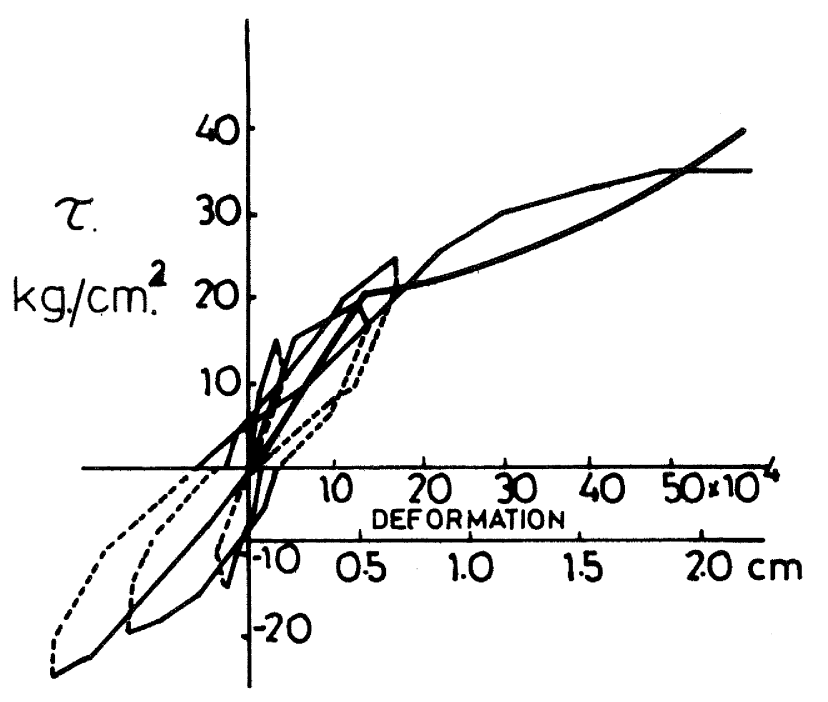

FIGURE 9: PERFORATED

WALL DIAGRAM

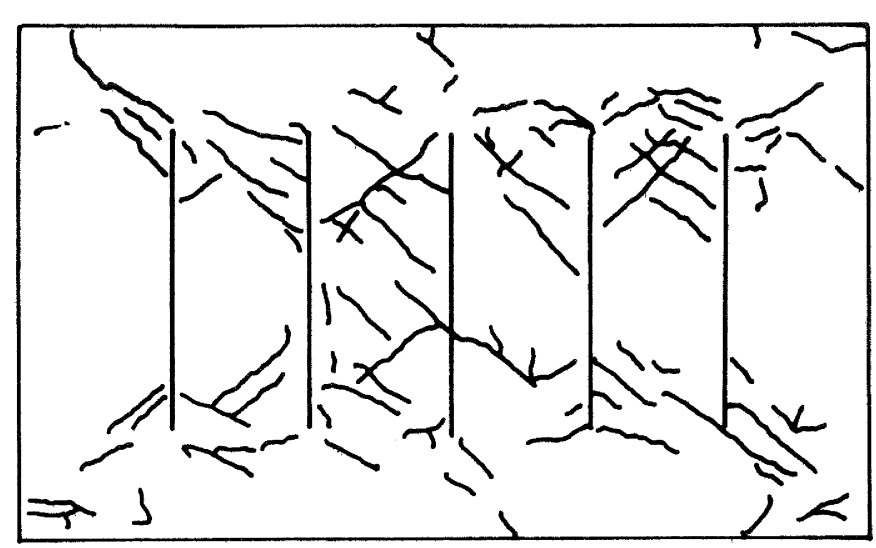

FIGURE 10: SKETCH OF CRACKS IN PERFORATED WALL IN PLASTIC RANGE

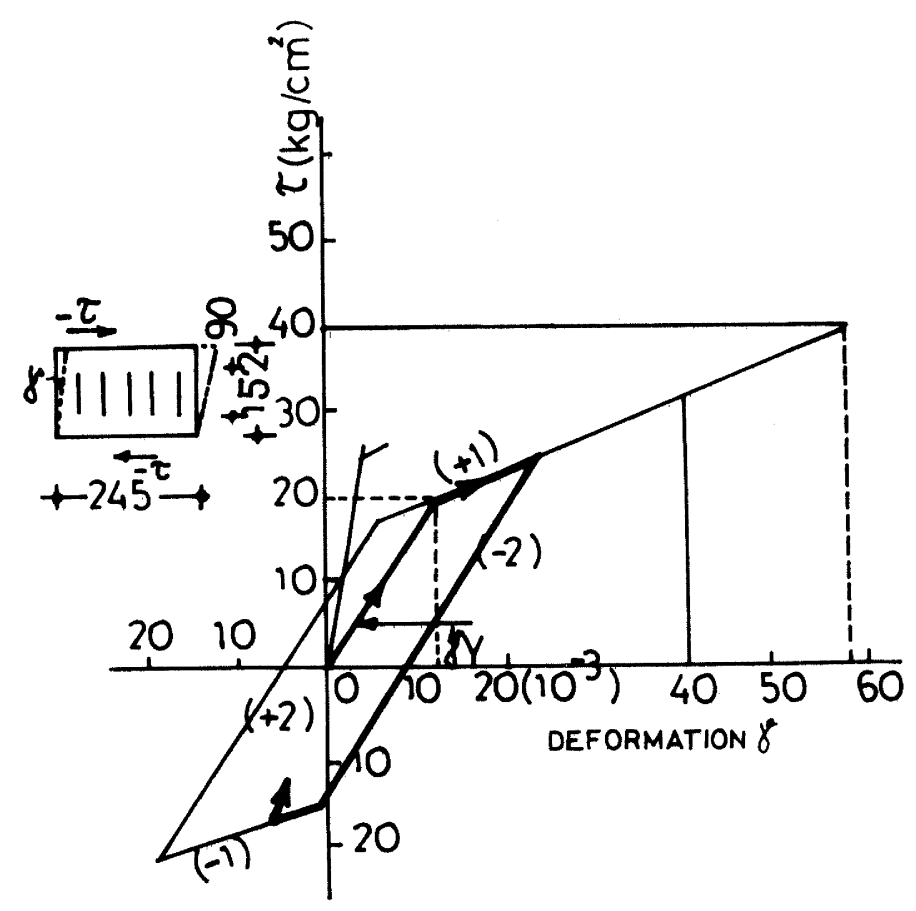

FIGURE 11: SCHEMATIC $\tau-8$ DIAGRAM USED FOR DYNAMIC ANALYSIS 

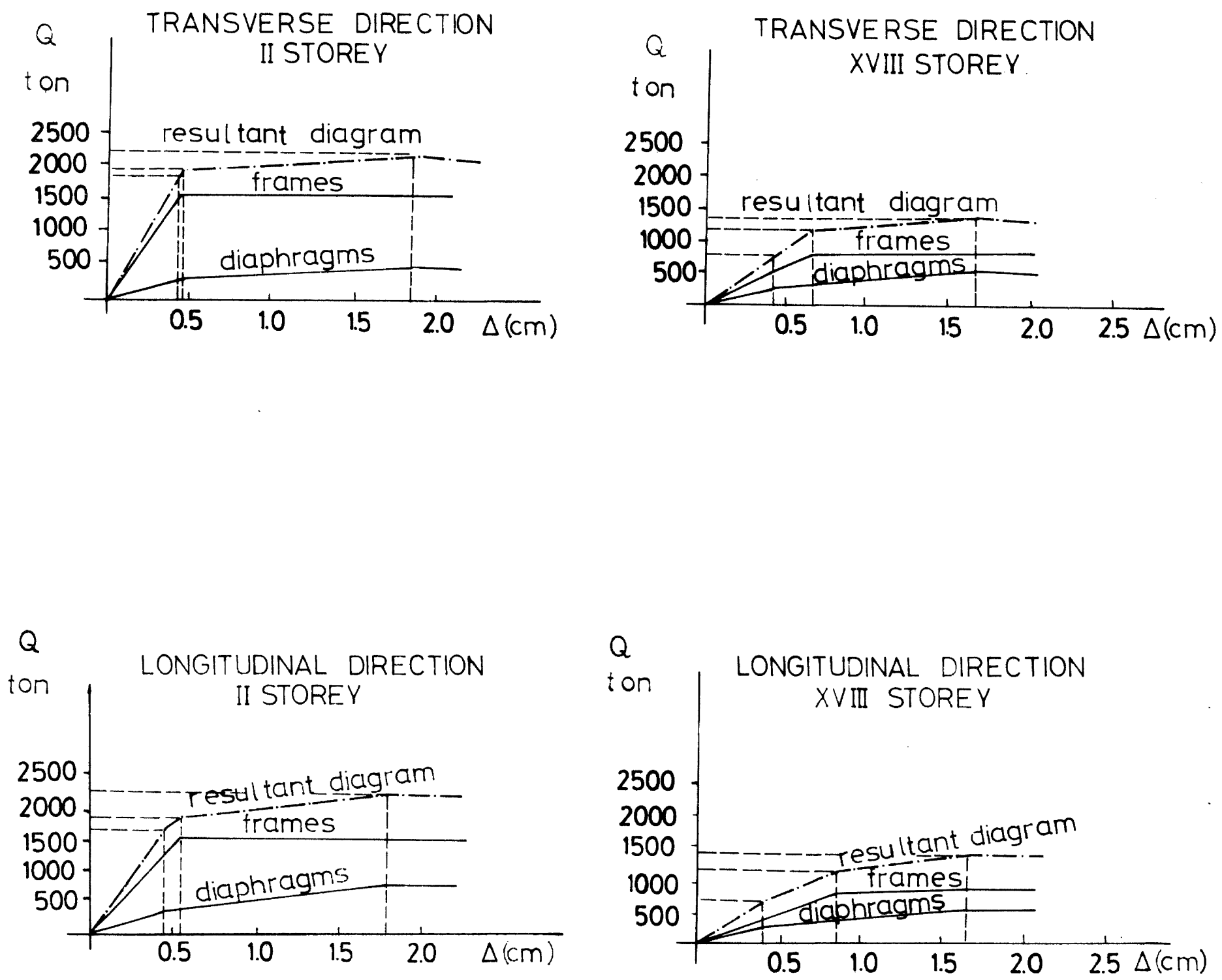

FIGURE 12: 
FINAL SYSTEM

Frame system strengthend by perforated diaphragms

DUCTILITY DIAGRAMS

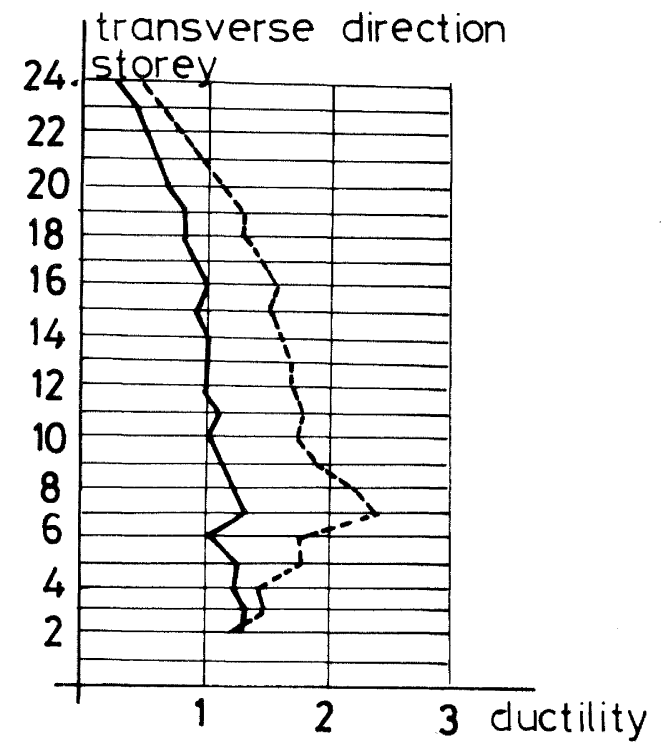

G

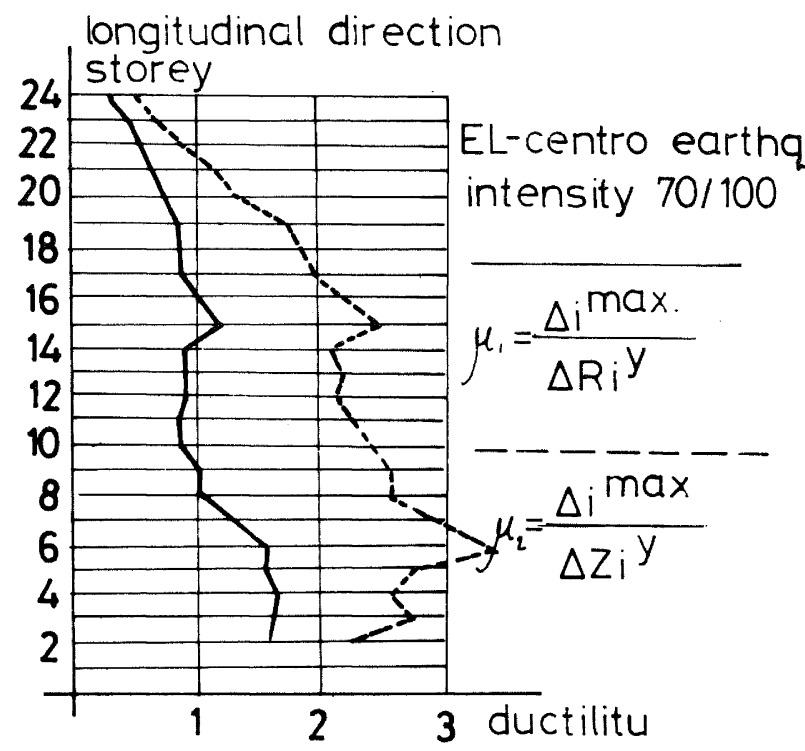

D.

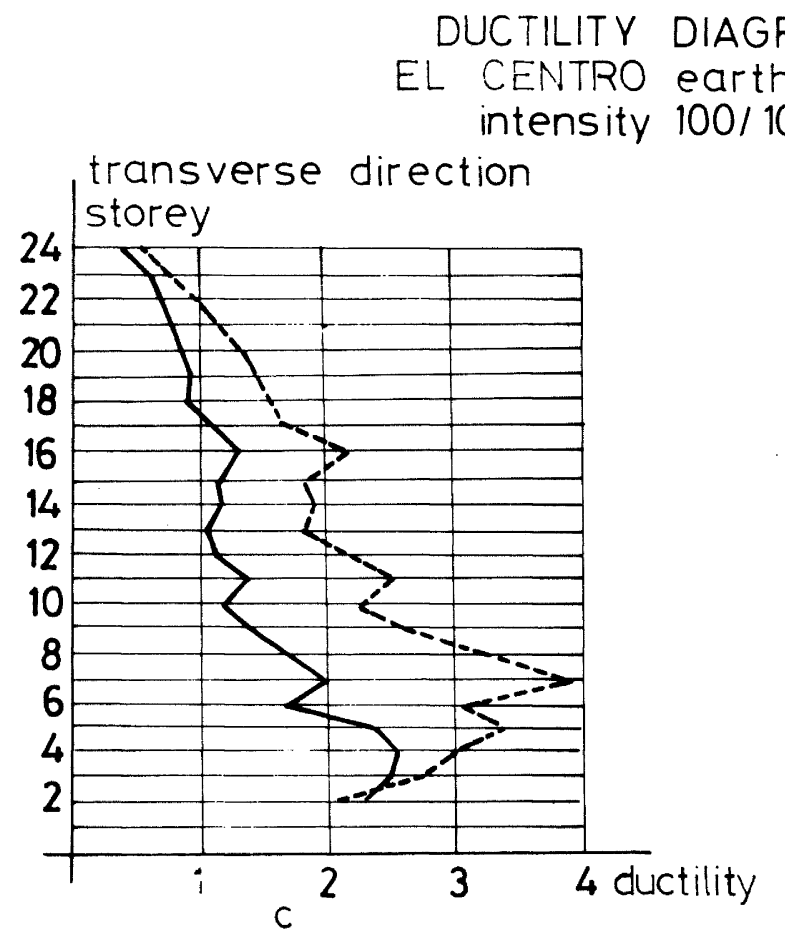

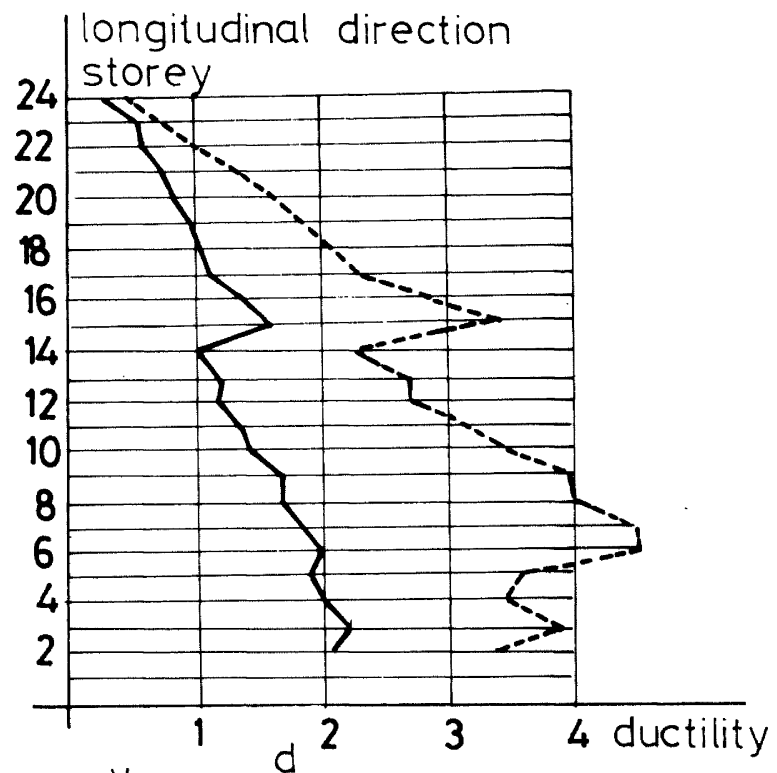

$\Delta R i^{Y}$-elastic displ. frame $\Delta \mathrm{Z} i$-elastic displ diaphragm $\Delta i^{\text {max }}$ - max. displacement 
FINAL SYSTEM:

Frame system strengthened by perforated diaphragms DUCTILITY DIAGRAMS
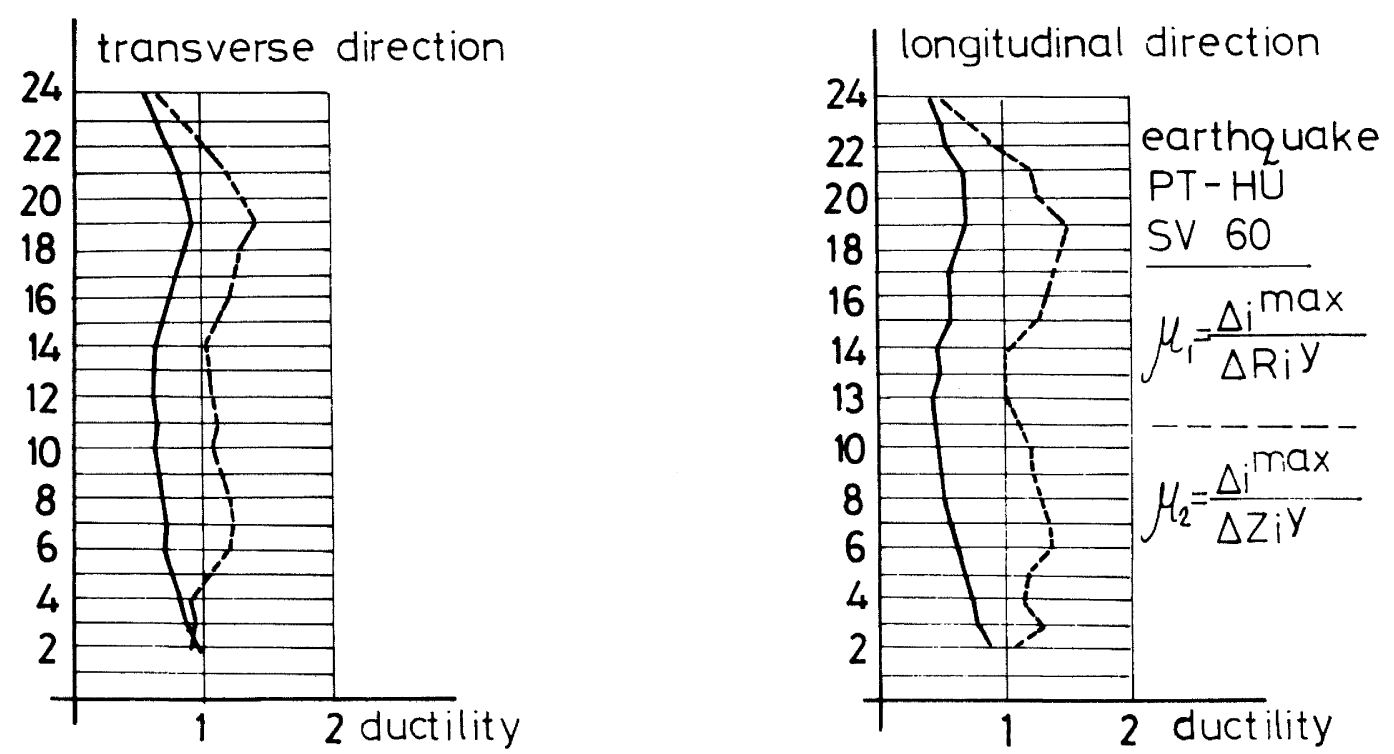

FIGURE 14 

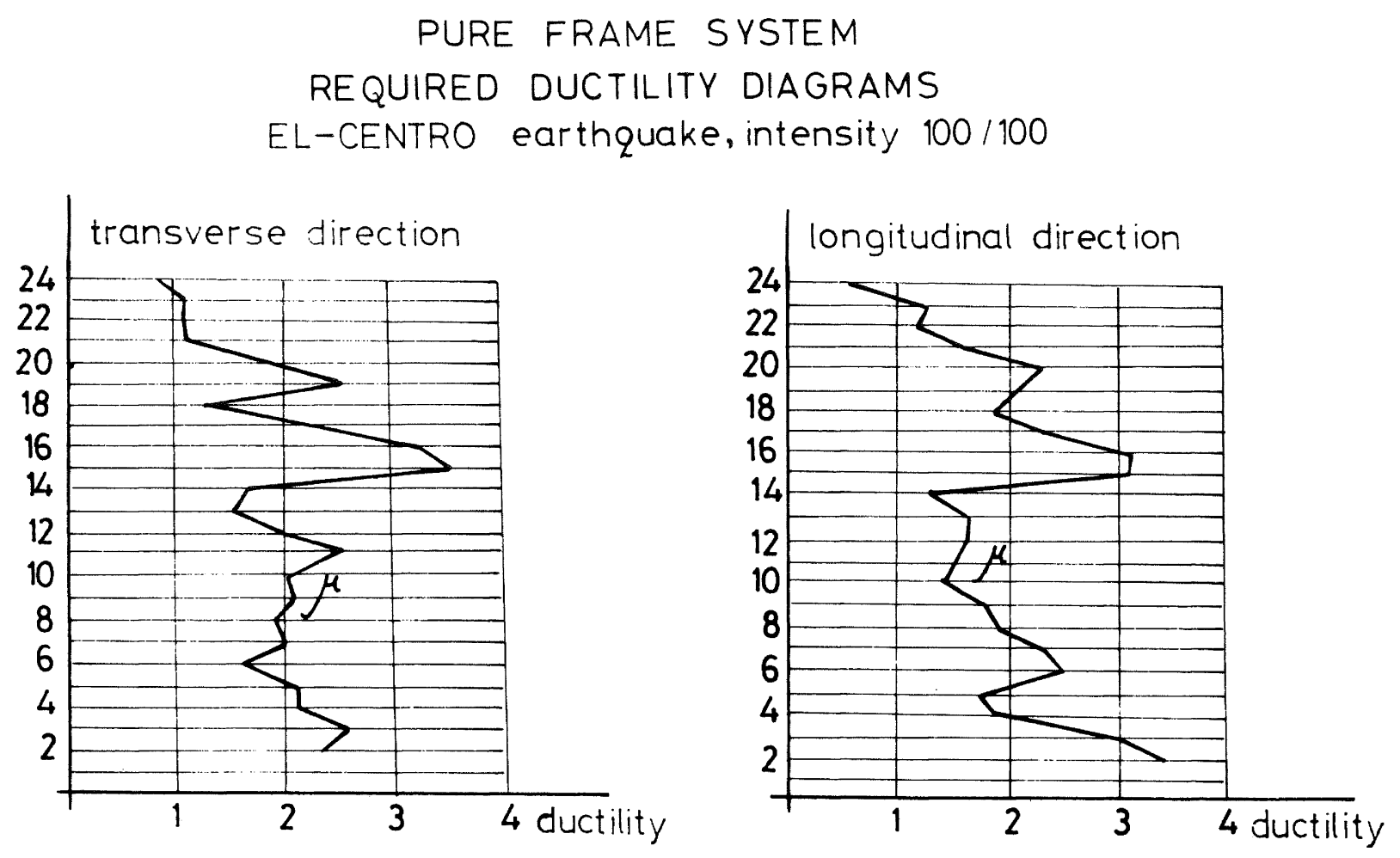
$\mu=\frac{\Delta i^{\mathrm{max}}}{\Delta i Y}$

DIAGRAMS OF MAXIMAL AND ELASTIC DISPLACEMENTS

EL-CENTRO earthquake intensity 100/100
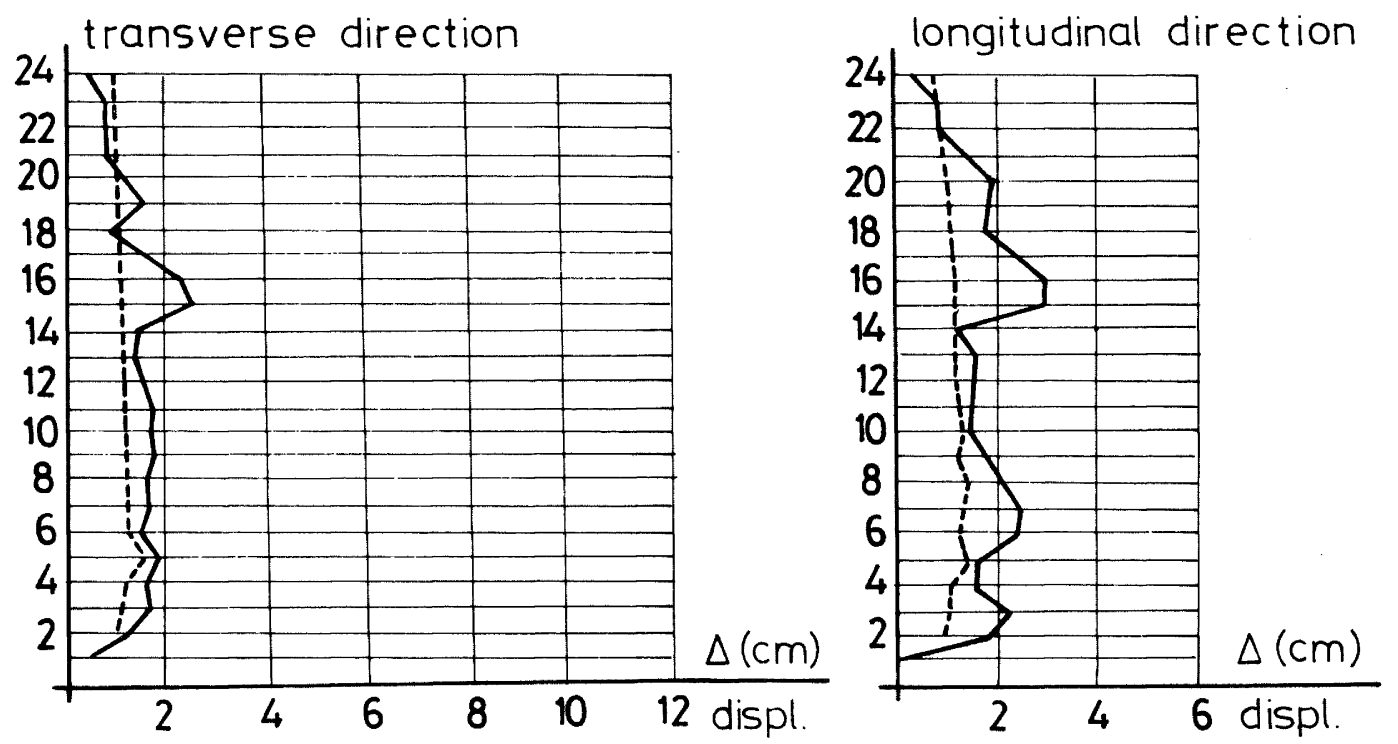
PLASTIC EXCURSIONS CRITERION

EL-CENTRO earthquake intensity $70 / 100$
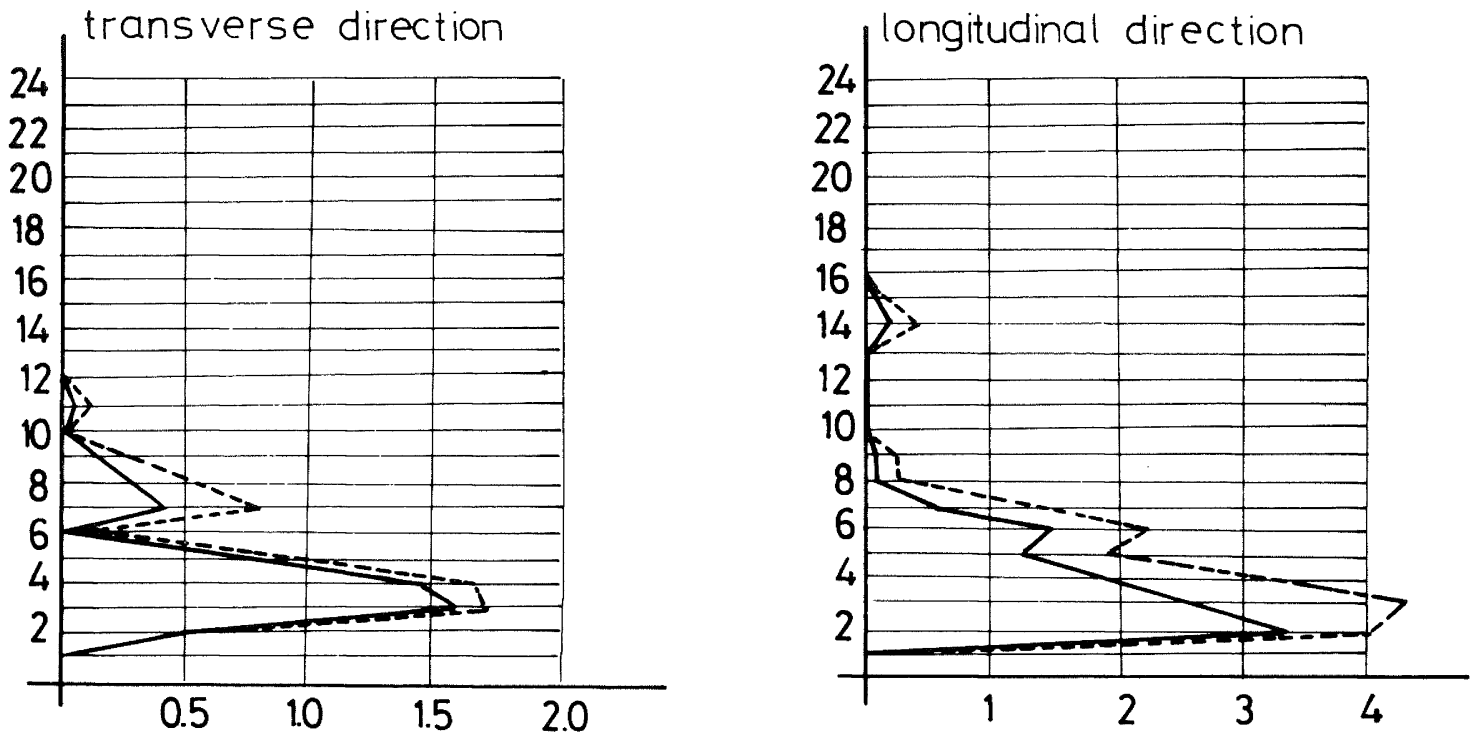

$$
\begin{aligned}
& \mu_{i}=\frac{|Y|}{\Delta R i^{Y}} \Delta R i^{Y} \text { elastic displ. of frame } \\
& ----\quad \mu_{2}=\frac{N \mid}{\Delta Z i^{Y}} \Delta Z{ }^{Y}{ }^{Y} \text { elastic displ. of diaphragm }
\end{aligned}
$$

\section{EL-CENTRO earthquake intensity 100/100}
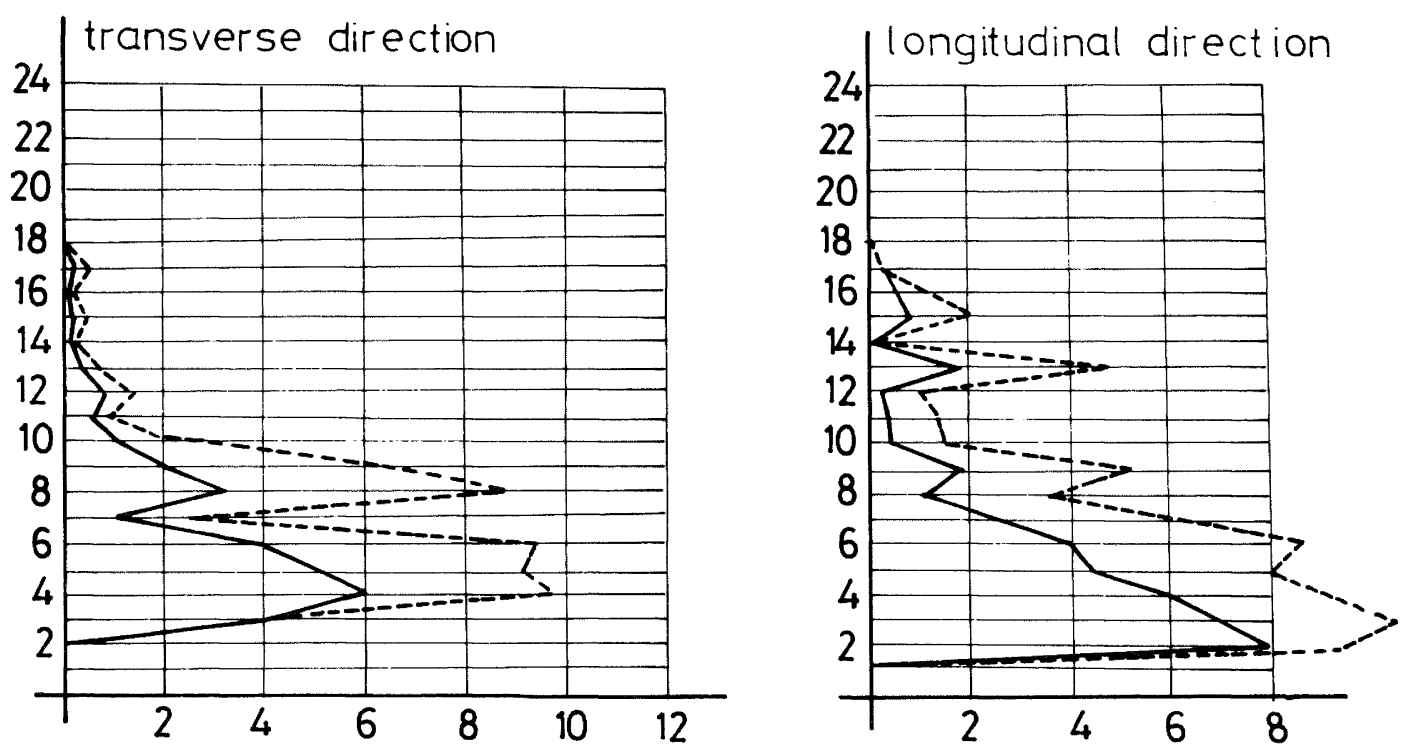